\title{
Nalar Zakir Abdul Karim Naik (Perspektif Aliran-Aliran Filsafat)
}

\section{Syefriyeni}

Fakultas Ushuluddin dan Pemikiran Islam

Universitas Islam Negeri Raden Fatah Palembang, Indonesia

Email: syefriyeni_uin@radenfatah.ac.id

\begin{abstract}
Abstrak
Sejak tahun 2004, sosok Zakir Abdul Karim Naik, yang biasa dipanggil Zakir Naik, melakukan pencerahan Islam yang sarat bernuansa logis, rasionalitas, ilmiah, bahkan filosofis. Pencerahan keagamaannya tidak dalam bentuk ceramah agama sebagaimana biasanya yang dilakukan oleh para ulama dan kiyai Muslim. Pertama tidak cenderung dilakukan di mesjid. Kedua, tidak cenderung dihadiri hanya oleh Muslim semata, namun justru banyak dari kalangan non Muslim, penganut agnotisisme, bahkan ateis sekalipun. Hal ini adalah suatu yang fenomenal. Nalar pemikiran Zakir Naik dapat dinyatakan merupakan bentuk gabungan antara nalar rasionalitas, nalar ilmiah, dan nalar religius. Alur-alur nalarnya dapat diukur dengan nalar filsafat, yang membentuk kontribusi jelas, baik di dunia da'i, dan dunia ilmiah. Bahwa dalam dunia ilmiah nalar Zakir Naik telah mampu menampilkan sebuah konsep integrasi ilmu, tujuan kehidupan, dan tujuan pengenalan terhadap hasil-hasil riset-riset ilmiah, yang tidak lain adalah untuk pendekatan dan pengenalan akan Allah SWT.
\end{abstract}

Kata Kunci: Nalar, Filosofis, Rasionalitas, Ilmiah, Religius

Sejak tahun 2004, data menunjukkan di berbagai mass media massa dan situs internet, bahwa sosok Zakir Abdul Karim Naik, yang biasa dipanggil Zakir Naik, melakukan pencerahan Islam yang sarat bernuansa logis, rasionalitas, ilmiah, bahkan filosofis. Pencerahan keagamaannya tidak dalam bentuk ceramah agama sebagaimana biasanya yang dilakukan oleh para ulama dan kiyai Muslim. Pertama tidak cenderung dilakukan di mesjid. Kedua, tidak cenderung dihadiri hanya oleh Muslim semata, namun justru banyak dari kalangan non Muslim, penganut agnotisisme, bahkan ateis sekalipun. Mulai dari kalangan mahasiswa, anak muda, praktisi akademik, kumpulan pedagang, tua dan muda, semua lini profesi dan keahlian, bahkan dukun, peramal, begitu juga dengan pendeta, penganut Hindu dan lain-lain, turut hadir di pencerahan keagamaannya. Penyampaiannya lebih dalam bentuk debat. Dan, luar biasa dari hasil pencerahan keagamaan yang dilakukan mampu membuat kalangan remaja mahasiswa dan lain-lain yang tadinya ateis, 
Syefriyeni

Nalar Zakir Abdul Karim Naik

(Perspektif Aliran-Aliran Filsafat)

agnotis, atau ada yang tidak respek dengan agama Islam, menjadi bersyahadat langsung di depan orang ramai, masuk Islam. Hal ini adalah suatu yang fenomenal.

Zakir Naik lahir pada tanggal 18 Oktober 1965 di Mumbai (Bombay pada waktu itu), India dan merupakan keturunan Konkani. Ia bersekolah di St. Peter's High School (ICSE) di kota Mumbai. Kemudian bergabung dengan Kishinchand Chellaram College dan mempelajari kesehatan di Topiwala National Medical College and Nair Hospital di Mumbai. Ia kemudian menerima gelar MBBS-nya di University of Mumbai. Tahun 1991 ia berhenti bekerja sebagai dokter medis dan beralih di bidang dakwah atau proselitisme Islam (Naik, 2017).

Naik mengatakan terinspirasi oleh Ahmed Deedat yang telah aktif di bidang dakwah selama lebih dari 40 tahun. Menurut Naik, tujuannya adalah "berkonsentrasi pada remaja Muslim berpendidikan yang mulai meragukan agamanya sendiri dan merasa agamanya telah kuno" dan adalah tugas setiap Muslim untuk menghilangkan kesalahpahaman tentang Islam untuk melawan apa yang ia anggap sebagai bias antiIslam oleh media Barat setelah serangan 11 September 2001 terhadap Amerika Serikat.

Thomas Blom Hansen, seorang sosiolog yang memegang posisi akademik di berbagai universitas, telah menulis bahwa gaya Naik mengabadikan Qur'an dan hadits dalam berbagai bahasa, dan bepergian ke berbagai negara untuk membicarakan Islam bersama para teolog, telah menjadikannya sangat terkenal di lingkungan Muslim dan non-Muslim. Meskipun ia biasa berbicara kepada ratusan hadirin, dan kadang ribuan hadirin, justru rekaman video dan DVD ceramahnya yang banyak didistribusikan. Perkataannya biasa direkam dalam bahasa Inggris, untuk disiarkan pada akhir pekan di sejumlah jaringan TV kabel di lingkungan Muslim Mumbai, dan di saluran Peace TV, which he co-promotes. Topik yang ia bicarakan mencakup: "Islam dan Ilmu Pengetahuan Modern", "Islam dan Kristen", dan "Islam dan Sekularisme", di antara yang lain.

Selain pujian terhadap Naik, ada juga yang berpandangan kontroversi. Analisis politik Khaled Ahmed menganggap bahwa Zakir Naik, menurut klaim superioritas Islam terhadap keyakinan religius lain, mempraktikkan apa yang ia sebut Orientalisme mundur. Dalam sebuah ceramah di Melbourne University, Naik mengatakan bahwa hanya Islam yang memberikan wanita kesamaan sejati. Ia menyatakan pentingnya penutup kepala dengan menganggap bahwa "pakaian Barat yang terbuka" membuat wanita lebih mungkin mengalami pelecehan seksual (Naik, 2017).

Intizar, Volume 24, Nomor 1, 2018 
Tanggal 21 Januari 2006, Naik mengadakan sebuah dialog antaragama dengan Sri Ravi Shankar. Acara ini mengenai konsep Tuhan dalam Islam dan Hinduisme, tujuannya ialah memberikan kesepahaman antara dua agama besar India, dan mengeluarkan kesamaan antara Islam dan Hinduisme, seperti bagaimana berhala dilarang. Diadakan di Bangalore, India dengan 50.000 orang memadati Palace Grounds.

Bulan November 2007, IRF mengadakan konferensi dan pameran Islam internasional 10 hari bertemakan Konferensi Damai di Somaiya Ground di Mumbai. Ceramah tentang Islam dilaksanakan Naik juga dua puluh cendekiawan Islam lainnya dari seluruh dunia (Naik, 2017).

Dari latar belakang masalah di atas, penelitian ini ingin melihat pada sisi logika Zakir Naik dalam memberikan penguatan pemahaman keagamaan, terutama golongan anak muda. Poin pentingnya adalah menganalisis nalar Zakir Naik, dalam pencerahan keagamaan kepada masyarakat. Seberapa penting menalar ini, penulis melihat dari sisi pendekatan filosofisnya. Bahwa pencerahan keagamaan dapat juga menggunakan gaya dan cara debat, logika, ilmiah, dan hal-hal yang jauh berbeda dengan ceramah kebanyakan. Penulis melihat model pendekatan dengan nuansa rasionalitas dan logika ini ternyata justru sangat mencerahkan bagi kaum-kaum terutama dari golongan non Muslim.

Yang menarik bagi penulis adalah, seperti apa betul nalar yang dikembang Zakir Naik, tatkala berdebat dengan Muslim, bahkan non Muslim. Jika berspektif dari kacamata filsafat, maka penulis ingin memberikan nuansa karakteristik nalar seorang Zakir Naik. Seperti apa karakteristik nalar seorang Zakir Naik yang telah membuat non Muslim, terpesona dan langsung masuk Islam disaksikan didepan khalayak ramai.

\section{Bangunan Nalar Zakir Naik}

1. Nalar Rasionalitas

a. Perdebatan dengan Dr. Matius

Ia mengatakan bahwa ia terlibat dalam creation, (versi Zakir Naik, ia mempunyai web dan organisasi creation), yang merupakan bagian dari creation internasional.

(DR. Matius) ... Sebagai dokter medis aku sangat tertarik dengan kedamaian. Dan, seperti yang kau sebutkan kedamaian itu bersifat internal dan eksternal. Sekarang secara pribadi, ketika ada jutaan orang merasa bersalah karena dosa dan bertaubat darinya, dan bahwa aku menerima dan percaya, bahwa 
Syefriyeni

Nalar Zakir Abdul Karim Naik

(Perspektif Aliran-Aliran Filsafat)

Yesus Kristus manusia yang tak berdosa membayar secara penuh atas dosaku, ia mengambil rasa maluku dan kesalahanku di tiang salib, dan mati untukku. Dan, karenanya aku berada dalam kedamaian. Dan, bahwa kedamaian adalah sesuatu yang berada diluar pemahaman. Aku ingin tahu apakah kau ingin merenggut kedamaian yang aku miliki yaitu kedamaian yang malampaui pemahaman, dan dapatkah kau menjelaskan itu?.

Jawab: Zakir Naik. Saudara, saya tidak ingin sama sekali merenggut kedamaianmu, yang aku inginkan adalah merenggut kedamaian palsumu, dan membuatmu mendapat kedamaian sejati. Saya cinta Yesus Kristus, aku menghormatinya dan aku mengaguminya. Aku ingin tahu apakah kau mencintai Yesus Kristus atau tidak ?, aku bertanya padamu, apakah kau setuju? dijawab Dr. Matius iya, lanjut Zakir Naik, apakah kau percaya Yesus adalah Tuhan?, Dr. Matius menjawab, iya.

Lanjut Zakir Naik, sekarang entah apakah kau mendapatkan kedamaian sejati, atau aku akan mengikuti kedamaianmu, correct, jika kedamaianmu benar, aku akan meninggalkan kedamaianku, dan aku akan mengikutimu, " $y a$ ”, jawab Dr. Matius. Lanjut Zakir Naik, kau memberitahuku bahwa Yesus Kristus adalah Tuhan, aku menantangmu, untuk menunjukkan satu ayat saja dalam Bibel, satu ayat saja, dan bukan ambigu dalam Bibel, dimana Yesus Kristus berkata, "Akulah Tuhan, atau sembahlah Aku,", maka aku siap masuk Kristen, kau berkata bahwa Yesus itu adalah Tuhan.

Ini adalah nalar positivisme, dimana Zakir Naik menantang Dr. Matius agar menunjukkan ayat dalam Bibel secara teks yang tegas dan terang tertulis disana, bahwa Yesus mengatakan "akulah Tuhan, sembahlah aku”. Ternyata tidak dijawab oleh Dr. Matius.

Jadi kalau Yesus tidak mengatakannya, kenapa kau percaya bahwa dia adalah Tuhan. Dan, dimana Yesus Kristus as berkata bahwa mati disalib untuk menebus dosamu. Itu adalah ajaran Paulus. Apakah kau mengikuti Paulus, atau mengikuti Yesus Kristus as?. Tidak ada dimanapun dalam Bibel. Dan, pertanyaanku adalah, ketika Yesus Kristus tidak pernah berkata bahwa ia adalah Tuhan. Jika kau mencintainya, kau harus menghormatinya.

Dia berkata ketika ditanya tentang perintah Tuhan yang utama, ini disebutkan dalam Injil Markus, 12.29, dia berkata, Syama Israilo, dengarlah hai orang Israel, Tuhan Allah kita, Tuhan itu Esa. Dia mengulangi apa yang dikatakan oleh Musa as. Sebelumnya. Jadi aku meminta padamu, jika kau mengetahui ajaran Yesus Kristus as. Jika kau berkata Kristen adalah orang yang mengikuti ajaran Yesus Kristus, as. 
Disebutkan dalam kitab Efesus 5: 18, dan janganlah kamu mabuk oleh anggur. Disebutkan dalam kitab Amsal 20:1, anggur adalah pencemooh, tidaklah bijak orang yang terhuyung-huyung karenanya. Kami Muslim tidak meminum alkohol, tapi banyak umat Kristen minum alkohol. Lebih jauh kami Muslim tidak makan babi, ini disebutkan dalam imamat 11: 7-8. Dalam kitab Bilangan, 14: 8, Yeyasa 65: 2-5, bahwa tidak boleh makan babi. Kami Muslim tidak makan babi, tapi hampir semua umat Kristen makan babi.

Lebih lanjut, Yesus Kristus as. disunat pada hari ke delapan, menurut Injil Lukas 2: 21. Kami Muslim disunat, sebagian besar Kristen tidak. Jika Kristen berarti seseorang yang mengikuti ajaran Yesus Kristus as. Aku dengan bangga mengatakan "Kami Muslim lebih Kristen daripada umat Kristen itu sendiri." Jadi, dimana ajaran Yesus Kristus yang berkata, bahwa kau harus menyembahnya ?. Jadi saudara, tunjukkan satu saja ayat dalam Bibel, dimana Yesus Kristus as. berkata dengan jelas, bahwa "Akulah Tuhan," atau "sembahlah Aku".

Zakir Naik (Lanjut); Hal yang harus diperhatikan adalah, Yesus Kristus tidak pernah mengaku sebagai Tuhan, faktanya jika kau melihat Injil Matius 19: 16-17. Ada seseorang mendatangi Yesus Kristus dan berkata, "Guru perbuatan baik apakah yang harus aku perbuat untuk memperoleh hidup yang kekal?, Jadi Yesus Kristus as. berkata, kenapa kau menyebutku baik ?, Hanya satu yang baik yaitu Allah di surga, dan jika kau ingin kehidupan abadi, turutilah perintah Tuhan. Dia tidak berkata, jika orang mau masuk surga, maka dia harus beriman, bahwa Yesus adalah Tuhan. Dia tidak pernah berkata, "Aku akan mati disalib untuk menebus dosadosamu. Yesus berkata, jika kau ingin masuk surga, kau taati perintah Tuhan. Dan perintah Tuhan adalah; kau tidak boleh mencuri, kau tidak boleh minum alkohol, kau tidak boleh memperkosa. Perintah Tuhan dilakukan dengan amal baik, bahwa amal baik akan membawamu ke surga. Yesus Kristus tidak pernah berkata, bahwa dia adalah Tuhan. Jadi mengapa kau berkata bahwa Yesus itu Tuhan?, kau juga tidak mengikuti ajarannya. (Z).

Aku tidak ingin berdebat soal apakah Yesus Tuhan atau bukan, aku katakan bahwa aku mempunyai kedamaian dalam hatiku, dan kedamaian itu ingin kubagi (M).

Sekarang pria mana, nabi mana setelah Yesus, yang memuliakan (Isa as.), dialah nabi Muhammad. Jadi nubuat tentang nabi Muhammad ini disebutkan dalam Bibelmu. Ada beberapa kutipan, aku bertanya padamu, kenapa kau tidak mengikuti instruksi Yesus Kristus as. dan, mengapa kau tidak mengikuti nabi Muhammad?, Kristen macam apakah kau ini?, apakah kau mengatakan aku tidak mengikuti ajaran 
Kristen ?, tidak sama sekali, aku memberikanmu ayat-ayatnya, referensi yang mana?, Kau pulang ke rumah, dan periksa sendiri Bibelmu, ayat yang mana?, kau bukanlah Kristen sejati. Akulah yang Kristen sejati. Mudah untuk menghakimi saudara, mudah, sangat mudah, aku memberikanmu ayat-ayatnya. Yang kau katakan. Kau belum memberikanku satu ayat saja (Naik, 2017).

b. Perdebatan dengan Srinian Padne

Namaku adalah Srinian Padne, Pertanyaanku adalah; Seperti yang kita ketahui bahwa, Tuhan Maha Kuasa. Jika Tuhan begitu Maha Kuasa, kenapa Dia tidak turun ke bumi, atau membersihkan dosa-dosa di bumi, membuatnya sebuah tempat yang sempurna untuk ditinggali, kenapa harus membutuhkan waktu yang sangat lama, misalnya kita tahu ada surga dan neraka. Manusia yang berbuat baik masuk surga, dan manusia yang berbuat buruk masuk neraka. Dia menguji kita. Kenapa Tuhan butuh waktu 6.000 tahun untuk menguji kita?

(Jawab Zakir Naik); Jadi begitu juga Tuhan telah menciptakan manusia dan telah memberikan kehendak bebas pada manusia. Semua makhluk lain ciptaan Tuhan tidak punya kehendak bebas, kecuali manusia dan jin. Para malaikat tidak punya kehendak bebas. Apapun yang difirmankan Tuhan mereka ikuti 100\%. Tapi manusia adalah makhluk yang lebih baik daripada malaikat. Setelah Tuhan telah memberikan kita kehendak bebas, maka jika kita menuruti perintah Tuhan, kita menjadi lebih baik daripada malaikat. Jika kita tidak menuruti perintah Tuhan, kita lebih hina daripada malaikat.

Jadi sekarang Tuhan telah memberikan kehendak bebas pada kita. Dan sebelum kita lahir ke duni ini, Tuhan telah bertanya kepada kita, "Siapa yang ingin menjadi manusia?, Jika kau tidak mau jadi manusia, tidak apa-apa, kau bisa menjadi gunung, pegunungan juga Muslim, atau pohon-pohon juga Muslim, para binatang juga Muslim, para malaikat juga Muslim. Muslim berarti “tunduk kepada Tuhan.” Semua binatang adalah Muslim. Semua tanaman adalah Muslim, semua malaikat adalah Muslim, tapi manusia adalah makhluk yang unik. Manusia adalah makhluk terbaik ciptaan Tuhan, Jadi, Tuhan bertanya "Siapa yang ingin menjadi manusia?, Qur'an berfirman bahwa kita bodoh karena memilih ingin menjadi manusia. (QS. AlAhzaab (33):72).

Itu artinya pas saja, atau jika kau mau menjadi manusia, maka ada..setiap dari kita,..Jadi, kita telah diberikan kehendak bebas. Dan, sekarang kita sedang menghadapi ujiannya. Jadi jika Tuhan meluluskan semua orang, maka Tuhan tidak adil. Jika Tuhan memasukkan semua orang ke surga, di surga misalnya aku adalah 
orang yang baik, tidak mencuri, tidak membunuh, sedangkan orang yang mencuri, membunuh, kok bisa masuk surga juga?, Aku akan memprotes kepada Tuhan "Kenapa kau juga memasukkan orang ini ke surga?" Jadi Tuhan berfirman dalam surat an-Nisaa"(4):40 bahwa dia tidak pernah mendzalimi siapapun sekecil apapun. Dengan demikian Tuhan Maha Penyayang, Dia memberikan kita kesempatan, Dia mengampuni kita, tapi Dia juga Maha Adil.

Jadi, berdasarkan ini, kita sedang menjalani ujiannya. Hidup ini adalah ujian untuk hari akhirat. Jadi kita adalah makhluk Tuhan yang unik. Dan tujuan dari penciptaan ini seperti yang difirmankan Qur'an dalam surat Dzaariyat (51):56, "Tuhan telah menciptakan manusia dan jin untuk menyembahNya." MenyembahNya berarti menuruti perintahNya. Jika kau mematuhi perintahNya, kau akan lulus ujian ini. Jika tidak Qur'an berfirman “Jika Tuhan mau, Dia bisa membuat semua orang menjadi Muslim.” Ini sangat mudah bagiNya. Tapi kita adalah makhluk yang sempurna, makhluk yang unik. Jika kita mematuhiNya, karena kita juga diberi kehendak bebas, maka kita lebih unggul. Semoga itu menjawab pertanyaanmu saudara./(S).. Terima kasih (Naik, 2017).

c. Perdebatan dengan Rajes

Namaku Rajes, Aku bekerja untuk perusahaan IT, sebelumnya aku ingin berucap 'assalamu'alaikum', Pak kau mempunyai kepribadian kharismatik dan pengetahuan tentang semua agama. Dan, kau selalu berkata bahwa hanya ada satu Tuhan, dan nabi Muhammad Saw adalah nabi terakhir. Dengan berbagai referensi dari ktab Hindu. Jadi, pertanyaanku adalah: Bagaimana dengan milyaran orang Hindu, Buddha, kepada siapa mereka beribadah? Apakah struktur mereka eksis ?, atau apakah hanya ada Allah saja? Terima kasih..

(Jawab Zakir Naik); Dia berkata telah mendengar ceramahku dimana aku berbicara tentang berbagai agama, dan aku telah membutktikan bahwa hanya ada satu Allah, dan nabi Muhammad adalah nabi terakhir, tidak hanya dari Qur'an, tapi juga dari kitab Hindu, Kitab Kristen. Jadi pertanyaannya adalah: Bagaimana dengan milyaran non-Muslim (orang Hindu, Kristen), apakah struktur mereka eksis ?.

Berkenaan dengan struktur mereka, jika kau membaca kitab mereka, semua kitab yang ada sebelum Qur'an, seiring berjalannya waktu telah diubah, dimanipulasi, dirusak. Karenanya jika kau menerapkan logika dan sains, tidak ada satu kitabpun yang lulus ujiannya kecuali Qur'an. Tapi keindahan dari ini adalah meskipun kitab agama lain telah diubah, entah itu Wedha, entah itu Ramayana, entah itu Mahabaratha, entah itu Bagavad Gita, entah itu Bibel, entah itu Dharma, 
meskipun mereka telah diubah, meskipun telah dirusak, masih ada sisa-sisa, masih ada banyak ayat yang membicarakan tentang keesaan Allah SWT, tentang tauhid. Meskipun kitab-kitab itu telah rusak, masih ada bagian yang berkata, bahwa nabi Muhammad adalah nabi penutup dan tarakhir. Jadi, jika mereka melakukan riset, dan jika mereka benar-benar ingin menjadi orang Kristen yang baik.

Seperti yang dikatakan Yesus Kristus a.s, dalam Gospel Yohanes 16: 12-14, "Masih banyak yang harus kukatakan kepadamu, tapi kamu belum dapat menanggungnya sekarang, tapi apabila roh kebenaran itu datang, ia akan memimpin kamu ke dalam seluruh kebenaran. Ia tak akan berkata dari dirinya sendiri, apa yang didengarnya itulah yang dikatakannya. Ia akan menuntun kamu ke dalam kebenaran. Ia akan memuliakan aku. Jadi, disini Yesus Kristus a.s, memberitahu para pengikutnya, bahwa akan ada nabi yang datang, nabi Muhammad Saw. " Jika aku memberikan pesan ini sekarang, kau tidak akan paham. Ketika dia datang, dia akan memimpinmu ke dalam seluruh kebenaran" (kata Yesus). Jadi, jika orang Kristen ingin menjadi Kristen sejati, dia harus mengikuti ajaran nabi Muhammad Saw.

Begitu juga dengan umat Hindu. Ada banyak ayat tentang Muhammad Saw, selain tauhid (keesaan Tuhan). Ada ayat tentang 'Kalki Avatar' (nabi terakhir yang akan datang), yaitu nabi Muhammad Saw. Jadi, jika kau ingin menjadi umat Hindu yang taat.., disebutkan dalam Kalki Purana bab 2 ayat 5, ayat 7, ayat 9, ayat 15 tentang Kalki Avatar, bahwa nama bapaknya adalah Vishnu Yash, yaitu hamba Allah atau Abdullah. Nama ibunya adalah Sumati, yang berarti kedamaian dan ketenangan, yaitu Aminah. Dia akan lahir di desa Shambala, desa kedamaian, yaitu Mekkah. Dia akan lahir dalam keluarga kepala suku Mekkah. Dia akan mempunyai empat orang sahabat, ini adalah empat Khulafaurrasyidin. Dia akan mendapatkan wahyu pertama dalam sebuah gua, yaitu gua Hira. Dia akan bermigrasi ke Utara dan kembali, dia pergi ke Madinah dan kembali. Ada banyak nubuat. Jadi, jika kau orang Hindu sejati, meskipun kitab ini telah rusak, telah dipalsukan, jika kau pikir kitab ini sepenuhnya firman Tuhan, kau harus mengikuti sang Kalki Avatar, kau harus beriman pada nabi penutup dan terakhir. Jadi, jika kau ingin mengikuti strukturnya, dan jika kau melakukan analisis, kau akan sampai pada nabi penutup dan terakhir, yaitu nabi Muhammad Saw.

Begitu juga dengan Buddhisme, begitu juga dengan Yudaisme, begitu juga Kekristenan, begitu juga Hinduisme. Jadi, apa yang kukatakan pada mereka berdasarkan surat dalam Qur'an, surat Ali Imran (3): 64, 'berpeganglah kepada suatu ketetapan yang tidak ada perselisihan antara kami dan kamu.", apa yang 


\section{Syefriyeni}

p-ISSN: 1412-1697; e-ISSN: 2477-3816

http://jurnal.radenfatah.ac.id/index.php/intizar

berbeda mari kita kesampingkan. Apa yang sama mari kita setujui, mari kita ikuti. Yang utama adalah bahwa kita tidak menyembah siapapun kecuali Allah. Jadi apa yang kita sadari, bahwa apapun yang berbeda akan kita diskusikan esok, apa yang sama, mari kita ikuti bersama.

Mari kita ikuti apa yang disebutkan dalam Bibel, dalam kitab Yahudi, kitab Kristen, kitab Hindu, yaitu Tuhan itu satu, Dia tidak punya berhala, tidak punya gambar, penyembahan berhala itu salah. Semua kitab menyebutkan tentang nabi terakhir dan penutup. Jadi, pertanyaanku pada mereka adalah: Kenapa kau tidak mengikutinya?, Kenapa kau tidak mengikuti dan beriman hanya pada satu Tuhan, jangan menyembah berhala, hanya menyembah Tuhan saja. Dan, kenapa kau tidak mengikuti nabi terakhir dan penutup?, dan pertanyaanku padamu saudara adalah: Jika kau orang Hindu...kupikir kau orang Hindu.. Benar ?, Jadi, kenapa kau tidak mengikuti kitabmu yang berkata bahwa Tuhan itu hanya satu ? Dikatakan "na tasya pratima asti" dalam Svetashvatara Upanishad bab 4 ayat 19, dalam Yajurveda bab 32 ayat 3, "na tasya pratima asti", "bagi Tuhan tidak ada pratima." Pratima artinya Tuhan tidak punya gambar, tidak ada foto, tidak ada lukisan, tidak ada potret, tidak ada patung, tidak ada pahatan, tidak ada berhalanya. Aku bertanya padamu: Apakah kau beriman pada satu Than?, (Rajes),,, Benar. Apakah kau percaya penyembahan berhala itu salah?, dijawab tidak. Ditanya Zakir Naik, jadi kenapa kau tidak mengikuti Wedhamu?,

(Penanya)..Aku akan mengatakan satu hal, kau tidak perlu berhala, gambar, atau lilin. Berhala diciptakan sehingga kau dapat berkonsentrasi. Bagi sebagian orang, mereka tidak bisa berkonsentrasi, jadi dibutuhkan berhala, agar mereka dapat berkonsentrasi dengan benar.

Rajes,,, Maaf, aku berkata bahwa berhala diperuntukkan untuk beberapa orang saja yang tidak bisa berkonsentrasi. Aku tidak berkata bahwa aku percaya...

(Zakir Naik),,, Jadi, itu artinya kau ingin mengecilkan Tuhan. Misalnya saudara, aku bertanya padamu: Kau membantu seseorang. Siapa namamu?, Rajeesh. Rajeesh kau membantu seseorang, misalnya di Srilanka. Setiap bulan kau mengirimkan 2.000 rupee padanya agar dia bisa bersekolah. Dia tidak tahu siapakah Rajeesh. Dia berkata "Siapa sih Rajeesh?, Aku tidak tahu." Jadi, apa yang dia lakukan?, Dia mengambil seekor kecoak, dan setiap pagi dia berkata "Rajeesh terima kasih. Rajeesh terima kasih." Apakah kau menyukainya?, dijawab..tidak. Apakah kau menyukainya?, dijawab tidak. Ini karena dia tidak tahu bagaimana rupa Rejeesh. Jadi dia mengambil kecoak untuk mewakili Rajeesh. Kau akan berkata padanya "Jika kau tidak tahu bagaimana rupaku, setidaknya cukup sebut namaku, 
Syefriyeni

Nalar Zakir Abdul Karim Naik

(Perspektif Aliran-Aliran Filsafat)

dan itu cukup. Kenapa kau menyimbolkanku dengan seekor kecoak?” Tuhan maha perkasa, apakah kau ingin mewakili Tuhan dengan berhala kecilmu (Naik, 2017).

d. Perdebatan dengan Rahul

Aku ada sebuah pertanyaan. Kau memberitahuku, bahwa kitab Wedha berkata "jangan buat gambar Tuhan.", siapapun yang menyembah makhluk, berarti melempar diri sendiri dalam kegelapan. Perbedaan antara Bhagwan dan Allah adalah, Allah berfirman, "Jika kamu menyembah siapapun selain Aku, maka Aku akan menghukummu selamanya, dan Aku takkan memaafkan dosamu." Tapi tidak pernah dinyatakan dalam kitab Hindu dimana Bhagwan berkata, "Jika kamu menyembah yang lain selain Aku, maka kamu akan kulempar ke dalam neraka selamanya." Maksudku adalah, konsep ketuhanan dalam Islam, Kekristenan, dan Yudaisme adalah sama, dimana Tuhan marah jika ada siapapaun yang menyembah selain diriNya. Tapi konsep Ketuhanan selain ketiga agama ini, yaitu Hinduisme, Buddhaisme, kupikir Tuhan dari agamaagama ini lebih berhati besar, karena Dia tidak berfirman bahwa "Aku akan memasukkanmu ke dalam neraka jika kamu tidak menyembah Aku." Meskipun aku paham bahwa menyembah berhala adalah perbuatan yang salah, menyembah makhluk adalah kesalahan, tapi aku merasa bahwa "Allah itu satu. Padanya bergantung segala makhluk. Dia tidak beranak dan tidak diperanakkan”, pada dasarnya tidak ada satu makhluk pun yang seperti Tuhan. Benar?, Jadi mengapa di dalam Qur'an, Bible, atau kitab Yahudi kita mengatribusikan emosi manusia pada Tuhan, misalnya ayahku memberiku sejumlah uang, dan aku memberikan uang itu kepada orang-orang miskin. Lalu pada suatu hari, jika aku lupa, maka ayahku merasa kecewa. Tapi ini adalah sifat manusia, Tuhan lebih berbesar hati daripada manusia, meskipun aku tidak menyembahNya, seharusnya Dia tidak memasukkanku ke dalam neraka, karena hal itu bersifat egoistik. Egoisme adalah bagian dari sifat manusia, bukan sifat Tuhan, inilah yang kurasakan menurut pikiranku.

(Jawab Zakir Naik); Pertanyaan yang sangat bagus, pertanyaan yang sangat cerdas, insya Allah kau akan menjadi yakin, aku tidak akan memintamu masuk Islam di hadapan publik, kita sudah membicarakan ini kemaren, oke. Sekarang Tuhan berfirman, bahwa Allah SWT tidak membutuhkanmu, dirimulah yang membutuhkanNya, sekarang masuk ke pertanyaannya, aku akan membuat pertanyaanmu menjadi lebih mudah. Kenapa kita harus mengucapkan AllahuakbarAllah Maha Besar?, Ketahuilah, Allah memintamu untuk mengucapkan Allahuakbar, Allah Maha Besar, katakanlah jika besok kau tidak mengucapkan 
Allahuakbar, apakah kau pikir kebesaranNya akan berkurang?. (R)..Tidak... (Z)...Tak peduli kau mengucapkannya atau tidak, Allah tetap Yang Maha Besar. Tak peduli kau mengucapkannya atau tidak, tak akan membuat perubahan, bahkan tak ada perbedaan pun, karena Allah dari dulu sudah Maha besar, tak peduli apakah kau mengucapkannya atau tidak.

Kenapa dia memintamu untuk mengucapkannya, itulah pertanyaannya, jawabannya adalah Allah SWT mengetahui psikologi manusia. Sebagai contoh, ibumu mengalami serangan jantung. Dan kau menghubungi seorang ahli jantung yang paling terkenal di dunia. Jika kau tahu bahwa dia terkenal, dia akan memberimu beberapa nasihat untuk ibumu, ada orang lain yang tak dikenal, dia datang dan memberimu nasihat, nasihat siapa yang akan kau ikuti? (R)... Aku akan mengikuti nasihat dari sang ahli./ (Z)..Kenapa? Karena kau tahu bahwa dia nomor 1, dia paling terkenal.

Jadi, Allah memintamu untuk memujiNya, bukan untuk diriNya, tapi untuk keuntunganmu sendiri. Karena pada saat kau memuji Allah, kau akan mengikuti nasihatnya. Dengan mengikuti nasihatnya, Allah tidak akan mendapat keuntungan, kau yang akan mendapat keuntungan. Ketika dokter memberikan nasihat padamu, kau mungkin akan memberinya keuntungan berupa bayaran. Tapi kau tidak memberikan bayaran apapun kepada Allah. Jadi Allah tidak mendapat manfaat apapun, tapi pada saat kau memujinya, manusia berkata, "Allah Maha Bijaksana, Allah Maha Besar, Allah Maha Penyayang." Yang Maha Bijaksana, -Dia memberikan nasihat yang aku ikuti; Yang Maha Besar-aku mengikutiNya, Maha Penyayang, aku mengikutiNYA. Jadi kau mengucapkan semua pujian ini bukan untuk keuntunganNya, namun untuk keuntunganmu sendiri.

(Zakir Naik)..Tuhan meyakinkan orang dalam cara yang berbeda-beda, beberapa orang suka logika dan akal sehat, kau adalah orang yang berpendidikan, kau lebih suka diyakinkan dengan logika, beberapa orang ingin rasa takut, beberapa orang ingin hukuman, beberapa orang ingin pahala. Ada 4 cara dimana Allah berfirman. Kau diyakinkan dengan akal sehat dan logika, kau seperti aku, kau seperti aku. Beberapa orang tidak diyakinkan dengan logika. Tapi ketika diimingi pahala.

Jadi disini Tuhan mengetahui psikologi manusia, Dia pencipta kita. Terkadang logika, terkadang akal sehat, terkadang pahala, terkadang hukuman. Tapi sekali berfirman Dia harus menepatinya, Dia tak bisa berbohong, sekali Dia berfirman, Dia harus tepati. Jadi Dia berusaha meyakinkanmu. 
Jadi Dia memberikanmu sebuah peringatan yang tegas. "Aku maafkan dosa yang lain." Misalnya pembunuhan. Itu adalah dosa kedua terbesar. Tapi ada satu dosa... jika kau menyembah orang lain, maka kau dapat melakukan apapun. Kau bisa saja membunuh, memakai narkoba, memperkosa, itu terlalu berbahaya. Ini sebuah petunjuk yang menyeluruh. Karena Dia adalah Sang Pencipta, Dia mengetahui, tidak ada Tuhan lain selain diriNya. Lalu orang lain mencoba bersikap seperti Tuhan, sedangkan Tuhan mengetahui tidak mungkin ada tuhan lain, ini sangat berbahaya. Itulah mengapa Dia berfirman bahwa menyembah siapapun, menuruti siapapun, kecuali Sang Pencipta, tapi bukan menuruti secara normal. Menuruti bagaikan menuruti ayahmu, tak masalah, menuruti ibumu, tak masalah, tapi menentang perintah Tuhan (Naik, 2017).

Jika menyimak perdebatan terakhir ini, seperti perdebatan 'ala-ala' para mutakalimin abad pertengahan. Hanya saja barangkali temanya sudah diperluas, dengan menggunakan bahasa dan kalimat-kalimat yang menyesuaikan dengan konteks zaman sekarang. Yaitu konteks serba ilmiah dan ilmu pengetahuan. Dan, istilah-istilah distingsi-distingsi akademik selalu muncul ke permukaan. Sangat menarik sekali jika ceramah keagamaan bernuansa logika, ilmiah, dan sains ilmu pengetahuan. Serta probalistik, contoh-contoh, dan perbandingan-perbandingan yang ada, sangat menggelitik dan mengusik logika kita (Nasution, 1986).

\section{Nalar Ilmiah}

a. Perdebatan dengan Adi

Namaku Adi, profesi dokter. Aku seorang Katholik Roma. Aku menjadi Katholik sudah 10 tahun. Tapi ketika aku menjadi Katholik, ada banyak pertanyaan. Poin pertanyaanku adalah apakah Yesus itu benar Tuhan, atau hanya utusan Allah ?, Tapi setelah aku melihat videomu di you tube, sering sekali. Satu per satu pertanyaanku telah terjawab. Jadi sekarang aku tidak percaya Yesus adalah Tuhan. Aku percaya pada satu Tuhan Allah SWT. Untuk menjadi Muslim atau Islam, ada dua hal yang diperlukan. Pertama, percaya pada satu Tuhan Allah SWT. Kedua percaya pada Muhammad sebagai utusan Allah. Sekarang aku percaya Muhammad adalah utusan Allah. Tapi berdasarkan keimananku, aku hanya mengetahui sedikit tentang Muhammad. Dapatkah kamu menjelaskan kepadaku agar aku merasa yakin tentang Muhammad sebagai nabi terakhir Tuhan?, sehingga aku bisa mendeklarasikan shahadat dengan sepenuh hatiku. 
(Jawab Zakir Naik); Manusia yang menulis sejarahnya dengan detil, tidak ada seorangpun yang mendekati dengan nabi terakhir nabi Muhammad Saw. Bahkan jika dijabarkan dengan sangat detil, bahkan jika aku berbicara berjam-jam, berharihari dan berbulan-bulan, aku tidak akan bisa melengkapi sirahnya (sejarahnya). Tapi dikarenakan pengetahuanmu yang sedikit tentang beliau, kamu setuju bahwa beliau adalah utusan Tuhan. Aku hanya akan memberikanmu pernyataan dari beberapa non-Muslim, apa yang telah mereka katakan tentang nabi Muhammad Saw.

Ada seorang yang bernama Michael H Hart yang menulis buku "100 Tokoh yang paling berpengaruh dalam Sejarah". Dan, dia adalah Kristen. Dia meletakkan nabi Muhammad Saw pada peringkat pertama. Dan, dia mengatakan... dia meletakkan Yesus Kristus a.s di peringkat ketiga, dan lalu Paul di peringkat keenam. Dia mengatakan jika kamu meletakkan pengaruh dari Yesus Kristus as. dan Paul digabungkan bersama-sama, Muhammad Saw lebih besar dibandingkan dengan penggabungan keduanya. Karena selain menjadi pemimpin agama, bahkan beliau juga sebagai pemimpin sosial dan sebagai pemimpin politik.

Jika kamu membaca buku "Heroes, Hero-Worship", oleh Thomas Carlyle. Dia orang Eropa, dia yang menulis. Dia meletakkan pada perinkat pertama Sang Pahlawan sebagai nabi adalah Nabi Muhammad Saw.

Jika kamu membaca pernyataan Jules Masserman, Jules Masserman, dia mengatakan, jika kecilnya sarana dan besarnya tujuan, dengan hasil yang mencengangkan. Jika tiga kriteria ini untuk menilai seorang pemimpin, kecilnya sarana, besarnya tujuan, dan hasil yang mencengangkan. Jika tiga kriteria ini untuk menilai pemimpin, maka tidak ada manusia dimanapun di muka bumi yang bisa dibandingkan mendekati dengan nabi Muhammad Saw.

Jadi, ini adalah ringkasan apa yang mereka katakan tentang nabi Muhammad Saw. Dan, Qur'an mengatakan dalam surat al-Qalam (68): 4, Allah SWT berfirman, "sesungguhnya kamu akan menemukan dalam Nabi Muhammad budi pekerti yang agung." Contoh terbaik dari umat manusia menurut Allah SWT adalah nabi Muhammad Saw. Dan, Allah berfirman dalam Qur'an surat al-Anbiya'(21): 107, "Dan, tiadalah Kami mengutus kamu, melainkan untuk menjadi rahmat bagi seluruh dunia, seluruh makhluk, seluruh umat manusia.” Jadi, nabi Muhammad Saw, adalah rahmat bagi seluruh umat manusia. Beliau merupakan rahmat.

Jika kamu ingin mengetahui sejarah hidupnya, aku meminta kamu agar membaca buku yang disebut dengan Rahiqul Makhtum. Yaitu tentang sejarah hidup dari Nabi Muhammad Saw. Buku ini mendapatkan penghargaan sebagai buku terbaik penulis singel. Aku ingin agar kamu membacanya dalam bahasa terbaik 
Syefriyeni

Nalar Zakir Abdul Karim Naik

(Perspektif Aliran-Aliran Filsafat)

yang bisa kamu mengerti. Entah itu dalam bahasa Ingris atau bahasa Indonesia. Ini akan memberikanmu ikhtisar dasar tentang sejarah hidup dari nabi Muhammad Saw. Semoga ini bisa menjawabmu secara singkat saudara. .. Kemudian bersyahadat.. dan yang bertanya masuk Islam (Naik, 2017).

\section{Nalar Religius}

a. Perdebatan dengan Abdul Razaq Khan

Namaku Abdul Razaq Khan bin Rustum Ali Khan. Dan pertanyaanku adalah; Apakah Islam itu sexist (tak setara dalam jenis kelamin), karena wanita tampak mendapat lebih banyak hak dibanding pria? Terima kasih.

(Jawab Zakir Naik); Islam sexist religion, sehingga wanita punya lebih banyak hak dibanding pria?. Masya Allah, ini adalah pertama kalinya aku ditanyakan pertanyaan ini. Aku sudah sering berceramah "Hak Wanita dalam Islam", karena di zaman sekarang media mengatakan bahwa Islam merendahkan wanita. Dan, ketika berceramah, aku selalu berkata bahwa tak ada yang bisa membantah bahwa Islam memberikan hak kepada wanita. Dan, ini pertama kalinya seseorang bertanya padaku bahwa apakah Islam memberikan lebih banyak hak kepada wanita?

Ya, dibandingkan agama lain, aku setuju denganmu. Dibanding dengan agama lain, Islam paling maksimal memberikan hak kepada wanita. Tapi secara keseluruhan, pria dan wanita dalam Islam itu sama. Tapi persamaan bukan berarti identik. Mereka sama, tapi tidak identik. Mereka sama. Dan, aku setuju denganmu, bahwa apa yang dikatakan media, bahwa wanita direndahkan, mereka dikekang, mereka terkebelakang, aku setuju denganmu bahwa dibandingkan agama lain. Islam memberikan hak paling maksimal. Jadi, itulah mengapa dalam ceramahku, aku membahas tentang hak wanita dalam Islam.

Jadi, ketika seseorang mendengar ceramahku, dia mungkin berpikir bahwa wanita dianggap lebih ditinggikan, wanita tidak lebih tinggi, mereka sama seperti pria. Keduanya sama, tapi kesamaan bukan berarti identik. Dan, aku akan memberimu contoh kecilnya. Jika dalam sebuah kelas, dua murid mendapat nilai 80 dari 100, keduanya selesai dalam waktu bersamaan. Keduanya dapat 80, murid A dan murid B. Ketika kau melihat lembar jawabannya, kita mengetahui, bahwa ada 10 pertanyaan, setiap pertanyaan bernilai 10 . Dalam pertanyaan pertama, murid A dapat nilai 9 dari 10. Dan, murid B dapat nilai 7 dari 10. Di pertanyaan nomor 2, murid B dapat nilai 9 dari 10, dan murid A dapat nilai 7 dari 10. Jadi di pertanyaan pertama, murid A lebih unggul dibanding B. Di pertanyaan kedua, murid B lebih 
unggul dibanding murid A. Pada pertanyaan sisanya dari 3 sampai 10, keduanya dapat nilai 8 dari 10. Jadi, jika kau jumlahkan, keduanya dapat 80 dari 100. Dari 3 sampai 10, keduanya identik, benar-benar sama. Tapi dalam pertanyaan 1, murid A lebih unggul. Dalam pertanyaan 2, murid B lebih unggul.

Sebagai contoh, jika seorang pencuri masuk ke rumahku, aku tidak akan berkata "Aku percaya persamaan wanita, pria dan wanita sama." Aku tidak akan menyuruh istri atau putriku untuk melawan pencurinya, karena Qur'an berfirman dalam surat Nisaa"(4):34, "Allah telah memberikan lebih banyak kekuatan pada pria." Qur'an berfirman, Arrijalu qauwamu alan nisaa'. "Pria adalah penjaga. " Banyak orang berpikir qawwam artinya "lebih unggul." Tidak. Qawwaam berasal dari akar kata aqama, yang artinya 'membela', jadi merupakan kewajiban pria untuk membela wanita. Dan ayatnya berlanjut,

Karena Allah telah memberikan kekuatan lebih pada pria." Jadi dalam kekuatan, pria punya kelebihan. Di sisi lain jika kau membaca hadist dari Muhammad Saw, dalam sahih Bukhari, vol. 8, dalam kitab adab, bab 2, hadist no 2, seorang pria menghampiri Rasulullah dan bertanya, "Siapa yang paling berhak mendapat cinta dan kasih sayang di dunia ini?, Rasulullah bersabda, "Ibumu." Pria itu bertanya " Setelah itu?" Rasulullah bersabda "Ibumu.", Pria itu bertanya lagi "Setelahnya?", Rasulullah mengulangi ketiga kalinya "Ibumu." Pria itu bertanya "Setelah itu siapa?, Barulah Rasulullah bersabda "ayahmu.", Itu artinya 75\% dari cinta dan kasih sayang diperuntukkan untuk ibu, 25\% untuk ayah. 2/3,3/4 dari cinta dan kasih sayang untuk ibu, $1 / 4$ untuk ayah. Singkatnya sang ibu dapat medali emas, medali perak, dan juga medali perunggu. Sang ayah harus puas dengan hadiah hiburan saja.

Jadi disini wanita mendapat keuntungan. Rasulullah Saw tercinta bersabda, "Ibumu yang mengandungmu selama 9 bulan, kau tidak bisa membalasnya meski kau memberikan segunung emas. Jadi disini, wanita mempunyai keunggulan. Disana pria mempunyai keunggulan. Jadi, tergantung pada situasinya, terkadang pria lebih unggul, terkadang wanita. Di banyak bidang lainnya mereka sama. Sebagaimana Allah berfirman dalam surat al-Ahzab (33): 35, Untuk pria dan wanita yang beriman.." Untuk pria dan wanita yang berzakat, yang shalat..dan ayatnya berlanjut. Jadi, di kebanyakan bidang keduanya sama. Dalam sebagian aspek yang pria lebih unggul, di aspek lain wanita. Semoga itu menjawab pertanyaanmu. (A) Terima kasih (Naik, 2017).

Penjelasan Zakir Naik soal kesetaraan gender antara pria dan wanita sangatlah proporsional dan jelas. Ada banyak penjelasan pakar lain misalnya soal kesetaraan 
gender ini. Ada yang menyamakan dalam segala hal. Misalnya jika pria bisa angkat berat, maka perempuan juga harus bisa angkat berat. Dan, kemudian justru malah menjadi beban bagi sebagian jenis gender lainnya. Dan, atau ada yang justru malah mengunggulkan sebagian jenis gender lainnya sebagai sebuah pembalikkan. Misalnya kalau dahulu, kebanyakan orang mengunggulkan laki-laki, maka banyak riset sekarang malah menemukan kelebihan-kelebohan perempuan. Namun, disebagian lainnya temuan kelebihan-kelebihan perempuan ini justru menjadi menghakimi bagi sebagian gender lainnya.

Karenanya menyimak penjelasan tentang kesetaraan pria dan wanita dalam penjelasan dan pandangan Zakir Naik, adalah menjadi jelas apa yang dimaksud dengan kesetaraan dan keseimbangan serta keadilan. Dimana, baik pria dan wanita memiliki keunggulan masing-masing, tergantung bagaimana kita memanfaatkan dan menyikapi keunggulan-keunggulan di masing-masing tipe gender tersebut. Inilah yang disebut Zakir Naik sebagai sebuah kesamaan.

\section{Pengaruh Nalar Seorang Zakir Naik Kepada Masyarakat Umum}

Debat dilakukan di ruang publik, dan sangat-sangat terbuka. Beragam fenomena, uraian, bahkan andaian-andaian yang mengajukan pertanyaan serta perdebatan. Dan, Zakir Naik selalu menggunakan nalar-nalar perbandingan, serta hal-hal yang sifatnya ilmiah, dengan nalar-nalar yang dibangun dalam kitab-kitab agama itu sendiri. Biasanya Zakir Naik selalu mencari titik persamaan apa yang tertulis dalam kitab al-Qur'an, Injil Bibel, dan kitab Budha. Namun, kesamaankesamaan itu justru mengundang debat yang tajam, dengan gaya nalar seorang Zakir Naik yang 'unik'. Unik dalam artian nalarnya menunjukkan keterbukaan dari rangkaian-rangkaian kalimat-kalimat yang dibangunnya. Mulai dari penelaahan teks kitab itu sendiri, kemudian mencari contah-contoh perbandingan pada fenomena-fenomena yang ada. Kemudian kembali ke teks kitab, dan mencari nalar dalam keilmiahan temuan sains modern. Dan, mencari nalar kembali kepada teks kitab itu kembali. Sehingga terlihat 'clear and clear'. Debat yang dibangun oleh Zakir Naik, adalah hampir mirip dengan cara debat dakwah gurunya yaitu Ahmed Deedat. Zakir Naik mengatakan, ia terinspirasi oleh Ahmad Deedat yang telah aktif di bidang dakwah selama lebih dari 40 tahun.

Dari semua itu dapatlah kita mengatakan bahwa nalar yang dibangun Zakir Naik sesungguhnya secara teleologis (tujuan akhir) adalah nalar yang berusaha membela dan pertahankan eksistensi ayat-ayat al-Qur'an yang sangat diyakini kebenarannya. Seberapapun upaya-upaya Zakir Naik adalah tak jauh dari upaya 
agar manusia dan umat yakin bahwa ayat-ayat al-Qur'an adalah sangat valid, kredibel, dan solit, sekalipun dilihat dari sisi manapun.

\section{Kesimpulan}

Mengkaji 'Nalar' Zakir Abdul Karim Naik (Perspektif Aliran-aliran Filsafat), adalah semacam riset yang ingin melihat bagaimana perkembangan nalar Muslim atau nalar yang bernuansa religius di dunia Islam.

Paling tidak riset ini adalah salah satu yang membuktikan bahwa sesungguhnya nuansa dan konteks berpikir nalar-nalar seperti itu masih ada di dunia suni, dan juga di dunia Islam bagian lainnya. Zakir Naik merupakan bukti sejarah 'hidup' yang menunjukkan bahwa nalar-nalar di dunia Islam yang dibangun oleh Muslim masih ada. Walaupun sangat banyak kritikan, namun sosok Zakir Naik, dan dakwah-dakwah ceramahnya adalah sisi unik di dunia Islam.

Saya hanya ingin menyatakan bahwa nalar dan kepentingan rasio dalam menjelaskan keagamaan masih sangat dibutuhkan. Kemandirian nalar, kalaupun tidak sampai membentuk sebuah mazhab seperti Muktazilah, namun neo antara Muktazilah dengan Asy 'ariyah dan rasional filosofis dapat disaksikan dengan sangat jelas pada nalar Zakir Naik. Dan, membentuk sebuah karakter nalar tersendiri lentur dengan zamannya.

Nalar pemikiran Zakir Naik dapat dinyatakan merupakan bentuk gabungan antara nalar rasionalitas, nalar ilmiah, dan nalar religius. Alur-alur nalarnya dapat diukur dengan nalar filsafat, yang membentuk kontribusi baik di dunia da'i, dan dunia ilmiah. Bahwa dalam dunia ilmiah nalar Zakir Naik telah mampu menampilkan sebuah konsep integrasi ilmu, tujuan kehidupan, dan tujuan pengenalan terhadap hasil-hasil riset-riset ilmiah, yang tidak lain adalah untuk pendekatan dan pengenalan lebih dalam akan Allah SWT.

Selain itu, jika melihat perdebatan Zakir Naik dengan beberapa orang non Muslim, atau beberapa orang Muslim yang meragukan keyakinannya sendiri, maka dapat dilihat perdebatan seperti ini mirip perdebatan ilmu kalam abad pertengahan. Hanya saja konteks dan nuansa menyesuaikan dengan zaman kini. Jika pada abad pertengahan perdebatan kalam serius pada soal-soal dosa besar, yang berawal karena dipicu oleh suasana politik Muslim, maka pada ceramah dan debat Zakir Naik keyakinan terhadap teks al-Qur'an, lebih dibangun dengan argumentasi hasilhasil riset suatu kajian-kajian ilmiah sebagai sebuah pembuktian. Dan, nalar rasio tetap dimainkan akan tetapi menyesuaikan dengan konteks zaman serta perkembangannya. 
Syefriyeni

Nalar Zakir Abdul Karim Naik (Perspektif Aliran-Aliran Filsafat)

Nalar Zakir Naik ini dipandang mampu menjawab kebutuhan zaman sekarang. Hal itu dipandang sebuah suguhan yang sesuai dengan zaman kini, dan sangat tepat untuk ditujukan bagi mereka-mereka non Muslim yang terpelajar atau Muslim terpelajar yang masih meragukan teks-teks suci agamanya. Bisa dikatakan bahwa nalar-nalar seperti ini, merupakan sebuah kebutuhan kini, baik di dunia Timur maupun di dunia Barat.

Bagitu juga dapat dinyatakan bahwa kerangka pemikiran ala-ala filsafat dan nalar tidak mati, baik di dunia Syi'i, maupun di dunia Sunni. Tergantung bagaimana bentuk-bentuk tersebut mengambil tempat dan menyesuaikan dengan kebutuhan zaman, terkait dengan proses peyakinan terhadap teks-teks suci al-Qur'an. 


\section{Daftar Pustaka}

Naik, Z. (2017, Maret 14). Retrieved from https://id.wikipedia.org/wiki/Zakir_Naik2017

Naik, Z. (2017, 7 1). Retrieved from https:/www.youtube.com/watch?v=gB0Fy8DjYs

Naik, Z. (2017, Agustus 2). Retrieved from https://www.youtube.com/watch?v=jPZvMZKaEek

Naik, Z. (2017, November 11). Retrieved from https://www.youtube.com/watch?v=85-gqAbmH-Y

Naik, Z. (2017, Agustus 28). Retrieved from https://www.youtube.com/watch?v=AAK12--L7Qc

Naik, Z. (2017, November 19). Retrieved from https://www.youtube.com/watch?v=PBbLIL49HE0

Naik, Z. (2017, Juli 3). Retrieved from https://www.youtube.com/watch?v=5MuyTC7iFTc

Nasution, H. (1986). Teologi Islam Aliran-aliran Sejarah Analisa Perbandingan. Jakarta: Universitas Indonesia (UI-Press). 
Syefriyeni

Nalar Zakir Abdul Karim Naik (Perspektif Aliran-Aliran Filsafat)

Intizar, Volume 24, Nomor 1, 2018 